a. Pediatric Research and Development Institute (Instituto de Desarrollo e Investigaciones Pediátricas, IDIP) "Prof. Dr. Fernando E. Viteri," Hospital de Niños "Sor María Ludovica," La Plata, Ministry of Health/ Scientific Research Commission (Comisión de Investigaciones Científicas, CIC), Province of Buenos Aires.

b. Biologics Institute "Dr. Tomás Perón," Ministry of Health of the Province of Buenos Aires.

c. Research and

Development Center for Catalytic Processes (Centro de Investigación y Desarrollo en Procesos Catalíticos, CINDECA), National Scientific and Technical Research Council (Consejo Nacional de Investigaciones Científicas y Técnicas, CONICET), School of Exact Sciences, Universidad Nacional de La Plata (UNLP).

d. Environmental Research Center (Centro de Investigaciones del Medio Ambiente, CIMA), School of Exact Sciences,

Universidad Nacional de La Plata.

E-mail address:

Enrique Martins,

Biochemist:

enriqueflmartins@

gmail.com

\section{Funding:}

This study was funded by the Health Research Scholarship granted by the National Ministry of Health of Argentina.

Conflict of interest: None.

Received: 1-12-2017 Accepted: 7-20-2017

\title{
Contribution of diet to lead exposure among children aged 1 to 7 years in La Plata, Buenos Aires
}

\author{
Enrique Martins, Biochemist ${ }^{a}$, Agustina Malpeli, B.S. ${ }^{a}$, Daniel Asens, B.S. ${ }^{a, b}$, \\ Luis Telese, Biochemist ${ }^{b}$,Victoria Fasano, Ph.D. in Mathematics ${ }^{a}$, Vania Vargas, B.S. ${ }^{a}$, \\ Marina Tavella, B.S. ${ }^{a}$ and Jorge E. Colman Lerner, M.D. ${ }^{c, d}$
}

\begin{abstract}
Introduction. Lead is a toxic metal which, even at low blood levels, can alter normal neurodevelopment in children, so no blood lead level is acceptable. Lead absorption from diet accounts for the highest contribution to blood lead levels in the population who is not exposed to contaminated environments or because of their occupation. The objective of this study was to determine the contribution of diet to lead exposure among children aged 1 to 7 years who attended Hospital de Niños de La Plata for health check-ups.

Population and methods. The study was conducted between June 2015 and May 2016. A questionnaire on the frequency of food intake was administered to 91 children whose average age \pm standard deviation was $3.0 \pm 1.7$ years, and foods included in the analysis were selected based on this questionnaire. Selected foods were purchased from different regional stores. Composite samples were made up of different food groups. Lead levels corresponding to each food group were determined and, finally, the daily intake of lead was estimated for the studied population.

Results. The daily intake of lead was $138 \mu \mathrm{g} /$ day. The food groups with the higher intake rates were processed meat products $(15.4 \%)$, bakery products $(14.8 \%)$, milk $(12.5 \%)$, and meat $(11.7 \%)$. Conclusions. Children aged 1 to 7 years attending a public hospital in La Plata have a lead burden from dietary intake of $138 \mu \mathrm{g}$ / day.

Key words: lead, child, diet.
\end{abstract}

http:/ / dx.doi.org/10.5546/ aap.2018.eng.14

To cite: Martins E, Malpeli A, Asens D, et al. Contribution of diet to lead exposure among children aged 1 to 7 years in La Plata, Buenos Aires. Arch Argent Pediatr 2018;116(1):14-20.

\section{INTRODUCTION}

Metals occur naturally in the Earth's crust and their environmental levels vary among the different regions. ${ }^{1}$ Lead enters the environment through natural and anthropogenic sources, such as the Earth's crust erosion, mining, combustion engine products, industrial effluents, production and final disposal of storage batteries, and some phosphorus fertilizers and pesticides, etc. These sources result in an environmental lead burden that remains on the Earth's crust, mainly on the water and the ground..$^{1,2}$ Environmental and health conditions during farming, breeding, processing, handling, and storing may affect the contamination of food products with environmental lead. ${ }^{3}$

Some metals are essential for human life because they play a biological role; ${ }^{4}$ others, such as lead, have no known biological function but they are known for their harmful effects on health. Over the last years, it has been demonstrated that low lead levels are associated with adverse effects on neuropsychological development in the first years of life that may result in decreased intelligence that may even persist after childhood. ${ }^{5}$ Since 2012, the United States Centers for Disease Control and Prevention (CDC) have established the reference blood lead level at $5 \mu \mathrm{g} / \mathrm{dL}$ for children, and $97.5 \%$ of children younger than 5 years in the US are under this value. ${ }^{6}$ However, the threshold for blood lead levels with no adverse events on neurodevelopment has not been established yet. ${ }^{7}$ Children are more vulnerable to lead exposure because they are at a higher risk of ingesting environmental lead due to their hand-to-mouth behavior; also, gastrointestinal absorption of lead is higher among children (25\%) than adults $(8 \%)^{1}$ and their developing nervous system makes them more vulnerable to the toxic effects of lead than if they had a mature brain. ${ }^{5}$ 
Several environmental, socioeconomic, and lifestyle factors may be considered determinants of high blood lead levels. ${ }^{8,9}$ Particularly for children with low exposure levels (blood lead level of $5-10 \mu \mathrm{g} / \mathrm{dL}$ ), it is believed that lead comes from multiple sources. ${ }^{10}$ Although some individuals are exposed to lead from contaminated environments or their occupation, for most part of the population, the main source of exposure is from diet. ${ }^{11} \mathrm{In}$ addition, mineral nutritional deficiencies, e.g. iron, calcium, and zinc, favor lead absorption, and vitamin deficiency, such as B-group vitamins and ascorbic acid, may exacerbate lead poisoning adverse events. ${ }^{4}$

The objective of this study was to determine the contribution of diet to lead exposure among children aged 1 to 7 years who attended Hospital de Niños de La Plata for health check-ups.

\section{POPULATION AND METHODS}

The study was conducted between June 2015 and May 2016 at the Pediatric Research and Development Institute (Instituto de Desarrollo e Investigaciones Pediátricas, IDIP) “Prof. Dr. Fernando E. Viteri," Hospital Interzonal de Agudos Especializado en Pediatría (HIAEP) "Sor María Ludovica" - Scientific Research Commission (CIC) of the Province of Buenos Aires.

This was an observational, analytical, crosssectional study based on the "total diet" or "market basket" methodology.

The studied population's sociodemographic characteristics are different from those of the general population, e.g., a $36 \%$ prevalence of households with unmet basic needs, more than $80 \%$ of households with contingent working conditions, and a $10 \%$ of mothers who did not complete primary education. ${ }^{12}$ The sample was selected by convenience, in a non-probabilistic fashion. Participants were children aged 1 to 7 years who attended a visit at the Health Observatory of IDIP. Children who were on a special diet due to a pathophysiological condition or whose parents (or tutor) did not agree to participate in the study were excluded.

The outcome measure "daily food intake" (DI) was defined using the median daily food intake as indicator. Its formula is detailed below.

$\mathrm{DI}=\mathrm{I} \times \mathrm{F} / 30.4$ (formula 1), where "I" means the median daily intake of food in $\mathrm{g} /$ day and " $\mathrm{F}_{i}$ " means the frequency of " $\mathrm{i}$ " intake, in days over a month. A month was assumed to have 30.4 days $(365 / 12){ }^{13}$
In turn, the outcome measure "food contamination with lead" was defined using the indicator lead level in the composite sample $(\mathrm{Cpb})$ for each food group, expressed in $\mu \mathrm{g}$ of lead $/ \mathrm{g}$ of food.

Finally, the outcome measure "lead dietary exposure" was defined using the indicator daily lead intake (Ipb), which was estimating using the following formula based on the two indicators mentioned above:

$$
\begin{aligned}
& \text { n } \\
& \mathrm{Ipb}=\sum \mathrm{Cpb}_{\mathrm{i}} \times \mathrm{ID}_{\mathrm{i}} \text { (formula 2) } \\
& i=1
\end{aligned}
$$

\section{Stages of the study}

\section{Stage 1. Survey on food intake}

To determine the DI indicator, a questionnaire on the frequency of food intake (Annex) was administered to the parents or tutors of children, who answered about food intake in the past month. The survey also included questions about the most commonly used brands and where the family acquired fresh and dried products. The survey on food intake was designed based on previous studies conducted at the institution ${ }^{14,15}$ and administered by professionals with a B.S. in Nutrition.

\section{Stage 2. Analysis of the survey on food intake and selection of foods to be analyzed. Food groups}

Once the survey on food intake was analyzed, we established which products covered $90 \%$ of the DI and selected those that would be purchased for lead determination. Based on the analysis of the survey results, foods were categorized into the following groups for analysis, as a composite sample: I. Bakery products, II. Grains, III. Eggs, IV. Oils and fats, V. Fruits, VI. Vegetables, VII. Meat, VIII. Meat products, IX. Milk, X. Dairy products, XI. Beverages, XII. Sweet snacks, XIII. Seasonings, XIV. Water.

\section{Stage 3. Purchase and preparation of selected foods}

Selected foods were acquired from different stores according to the answers provided in the survey on food intake as follows: industrially produced foods were purchased from a hypermarket or, if not available there, from a retail store. Fresh products were acquired from four stores: a hypermarket and three different retail stores. 
Foods were prepared ordinarily for consumption, separately, and in the most representative manner (raw, washed, peeled or cooked in doubly distilled water using stainless steel utensils); non-edible parts were discarded. Solid foods were homogenized using a stainless steel hand blender. Composite samples were prepared based on the proportion of each food according to the survey answers.

\section{Stage 4. Lead determination}

Approximately $0.5 \mathrm{~g}$ of each composite sample was weighted and placed into containers that were safe for microwave digestion heating and pressure. Then $8 \mathrm{~mL}$ of nitric acid 65\% (Merck EMSURE, Darmstadt, Germany) were added by dripping; and then $1 \mathrm{~mL}$ of hydrogen peroxide 30\% (Merck EMSURE, Darmstadt, Germany) was added. Digestion was done using a CEM MDS2000 microwave digester (CEM Corporation, Matthews, USA). Finally samples were brought to a $25 \mathrm{~mL}$ volume with doubly distilled water and stored at $-20{ }^{\circ} \mathrm{C}$ in plastic containers until analysis. The $\mathrm{Cpb}$ in the digested samples was determined using an Agilent 4100 MP-AES microwave plasma-atomic emission spectrometer (Agilent, Santa Clara, CA, USA), at a $405781 \mathrm{~nm}$ wavelength. Doubly distilled water blanks used to cook foods before and after boiling and reagent blanks were analyzed.

\section{Analysis of results}

The SPSS 18 software was used for statistical data analysis. The Ipb was estimated using formulas 1 and 2.

A comparison was done of the Ipb estimated using the provisional tolerable weekly intake (PTWI) of $25 \mu \mathrm{g} / \mathrm{kg}$ of body weight, valid from 1993 to 2010, when new recommendations were issued by the Food and Agriculture Organization (FAO) of the United Nations. ${ }^{16}$

\section{Ethical aspects}

The study protocol was approved by the Institutional Research Protocol Review Committee (Comité Institucional de Revisión de Protocolos de Investigación, CIRPI) of Hospital de Niños "Sor María Ludovica." Personal data were collected according to article 3 of National Law No. 25326 for Personal Data Protection. In all cases, a written authorization in the form of a free, informed, and express consent was obtained from parents or tutors following a detailed explanation of the study's procedures and objectives.

\section{RESULTS}

Surveys on food intake were administered to the parents or tutors of 91 children whose average age \pm standard deviation (SD) was $3.0 \pm 1.7$ years. Sixty-six percent were males. Most survey respondents (59\%) came from the south west area of La Plata, made up of the following neighborhoods: Los Hornos, Altos de San Lorenzo, Olmos, and Villa Elvira. The west area was the second most represented area $(41 \%)$, made up of the San Carlos, Melchor Romero, Abasto, and Gorina neighborhoods.

Table 1 lists the food products that covered $90 \%$ of the daily intake altogether, grouped into composite samples. The total Ipb was $138.2 \mu \mathrm{g} /$ day. The food groups with the higher intake were processed meat products $(15.4 \%)$, followed by bakery products $(14.8 \%)$, milk $(12.5 \%)$, and meat $(11.7 \%)$. These food groups altogether accounted for more than $50 \%$ of lead intake.

\section{DISCUSSION}

Foods that covered $90 \%$ of the DI according to the survey mainly overlap with the foods most frequently referred for children between 6 months old and 5 years old in the 2007 National Survey on Nutrition and Health (Encuesta Nacional de Nutrición y Salud, ENNyS). ${ }^{17}$ The Ipb estimated in our study is higher than that of most countries (Table 2) included in the comparison, except Chile. Although the Ipb in these studies was assessed for the general population, it has been observed that the estimated lead intake does not vary greatly among the different age groups. ${ }^{18}$

The lead intake estimation did not include the contribution of water from beverages because it was very difficult to estimate its median daily intake. However, considering daily water consumption requirements, it may have a considerable contribution. For children 1 to 3 years, the daily requirement of water from beverages is $900 \mathrm{~mL}$ and for children 3 to 7 years, $1200 \mathrm{~mL} \cdot{ }^{19}$ Assuming that all children in our study met the water intake requirements and subtracting the milliliters corresponding to other beverages (juice, soft drinks, and milk), we established a water intake of $320 \mathrm{~mL}$. Based on this, the lead intake from running water would be approximately $48 \mu \mathrm{g} /$ day, which would raise the total Ipb to $186.2 \mu \mathrm{g} /$ day.

The food groups with the highest contribution to lead dietary exposure vary greatly among the different geographic regions. According to the European Food Safety Authority (EFSA), the 
food groups that contributed the most to lead exposure in the European population included bread, toasts, soups, vegetables, fruits, water, nonalcoholic beverages, alcoholic beverages, sugar and confectionery. ${ }^{16}$ In total diet surveys conducted in the USA between 1991 and 2005, the foods with the highest lead intake included sweet cucumber pickles, milk chocolate candy bars, canned fruit cocktail, chocolate syrup, canned potatoes, canned apricots, and shrimps. ${ }^{16}$ In the SCOOP study, conducted in 2004 in 10 European countries, the highest lead levels were found in herbs and spices, followed by game meat, dietetic food, food supplements, and wine. ${ }^{13}$ In Chile, the highest lead levels were determined in sugar, fruits, and spices. Other foods that contributed to dietary lead exposure included bread, dairy products, and meat. ${ }^{18}$ In Spain, Llobet et al. found that foods that contributed the most to dietary lead exposure among males in all population groups were grains.

TABLE 1. Components of each composite sample and their median daily intake. Lead levels of the composite sample based on wet weight and daily intake of lead

\begin{tabular}{|c|c|c|c|c|}
\hline Composite sample & Components & Median DI (g/day) & $\mathrm{Cpb} \mu \mathrm{g} / \mathrm{g}$ & $\mathrm{Ipb} \mu \mathrm{g} / \mathrm{day}$ \\
\hline I. Bakery products & $\begin{array}{l}\text { Bread } \\
\text { Salt crackers } \\
\text { Sweet cookies } \\
\text { Filled biscuits } \\
\text { Breadcrumbs }\end{array}$ & $\begin{array}{l}40 \\
14 \\
16 \\
21 \\
13\end{array}$ & 0.197 & 20.5 \\
\hline II. Grains & $\begin{array}{l}\text { Noodles } \\
\text { Rice } \\
\text { Frosted flakes }\end{array}$ & $\begin{array}{c}28 \\
27 \\
7\end{array}$ & 0.070 & 4.4 \\
\hline III. Eggs & Eggs & 5 & 0.160 & 0.8 \\
\hline IV. Oils and fats & $\begin{array}{l}\text { Oil } \\
\text { Butter }\end{array}$ & $\begin{array}{c}25 \\
4\end{array}$ & 0.412 & 11.9 \\
\hline V. Fruits & $\begin{array}{l}\text { Banana } \\
\text { Apple } \\
\text { Tangerine } \\
\text { Orange }\end{array}$ & $\begin{array}{l}50 \\
50 \\
50 \\
50\end{array}$ & 0.055 & 11.0 \\
\hline VI. Vegetables & $\begin{array}{l}\text { Squash } \\
\text { Carrot } \\
\text { Chard } \\
\text { Potato } \\
\text { Tomato } \\
\text { Lettuce }\end{array}$ & $\begin{array}{c}36 \\
23 \\
9 \\
21 \\
6 \\
18\end{array}$ & 0.080 & 9.0 \\
\hline VII. Meat & $\begin{array}{l}\text { Fatty beef } \\
\text { Semi-fatty beef } \\
\text { Chicken }\end{array}$ & $\begin{array}{l}30 \\
28 \\
30\end{array}$ & 0.185 & 16.2 \\
\hline VIII. Processed meat products & $\begin{array}{l}\text { Breaded chicken } \\
\text { Chicken nuggets } \\
\text { Vienna sausages }\end{array}$ & $\begin{array}{l}30 \\
30 \\
11\end{array}$ & 0.299 & 21.2 \\
\hline IX. Milk & Whole milk & 224 & 0.077 & 17.2 \\
\hline X. Dairy products & $\begin{array}{l}\text { Whole-milk yogurt } \\
\text { Creamy cheese } \\
\text { Grated cheese }\end{array}$ & $\begin{array}{c}53 \\
7 \\
4\end{array}$ & 0.180 & 11.5 \\
\hline XI. Beverages & $\begin{array}{l}\text { Orange juice (powder) } \\
\text { Soft drink }\end{array}$ & $\begin{array}{c}299 \\
57\end{array}$ & 0.030 & 10.8 \\
\hline XII. Sweets and sugar & $\begin{array}{l}\text { Sugar } \\
\text { Gelatin } \\
\text { Dulce de leche } \\
\text { Cookie sandwich }\end{array}$ & $\begin{array}{c}10 \\
7 \\
4 \\
5\end{array}$ & 0.118 & 3.1 \\
\hline XIII. Seasonings & Mayonnaise & 3 & 0.207 & 0.6 \\
\hline XIV. Running water & & & 0.151 & \\
\hline Total Ipb & & & & 138.2 \\
\hline
\end{tabular}

DI: daily intake. $\mathrm{Cpb}$ : lead levels of the composite sample based on wet weight. Ipb: daily intake of lead from the composite sample. 
Among females, although grains made a major contribution, fish and shellfish contributed the most to lead intake. Other quantitatively important foods included fruits and vegetables. ${ }^{20}$

In this study, the food groups that contributed the most to lead intake did not reflect what had been reported by the EFSA, the US or the SCOOP study, but showed certain similarity with the Chilean study by Muñoz et al. and the Spanish study by Llobet et al.

The weekly lead intake, based on our estimation, widely exceeds the PTWI of lead valid up to 2010, which was $25 \mu \mathrm{g} / \mathrm{kg}$ of body weight, considering an extreme case of a $30 \mathrm{~kg}$ child (i.e., a 7 year-old child with an adequate weight, up to the $97^{\text {th }}$ percentile). ${ }^{21}$ The PTWI in that case would be $750 \mu \mathrm{g}$ of lead per week $\left(30 \mathrm{~kg}{ }^{*} 25 \mu \mathrm{g} / \mathrm{kg}\right.$ ), below the median weekly lead intake established in our study, which was $967.4 \mu \mathrm{g}$.

It is worth noting that, in 2010, the Joint FAO/ World Health Organization (WHO) Expert Committee on Food Additives and the EFSA Panel on Contaminants in the Food Chain (CONTAM) concluded that the PTWI at $25 \mu \mathrm{g} / \mathrm{kg}$ of body weight was not adequate because there was no evidence of a threshold in relation to critical developmental pathologies in children, including neurotoxicity. Therefore, it was not possible to establish a new PTWI that could be considered "protective" of health. ${ }^{16}$

Childhood lead exposure in our population was recently estimated at a relatively low median blood lead level of $2.2 \mu \mathrm{g} / \mathrm{dL},{ }^{12}$ and no specific sources of exposure were identified, so the dietary contribution to lead burden could be relevant.

The ubiquity of lead in the environment, especially in the water and dust, makes poor sanitation conditions in food production, processing, storing, and presentation for sale become potential explanations for the lead burden observed in foods. Further studies are required to assess this hypothesis. A better control of sanitation conditions in relation to food production and provision activities may reduce their lead burden. In addition, promoting the consumption of foods containing minerals and vitamins that modulate lead effects may mitigate lead exposure and / or any damage caused by this element. For example, a low calcium diet increases lead absorption and toxicity; ironpoor diets, that lead to iron deficiency, may increase lead absorption and retention. ${ }^{7}$ There is evidence that the presence of zinc in the gastrointestinal tract may reduce lead absorption. In animal studies, it has been demonstrated that selenium may reduce the neurotoxic and nephrotoxic effects of lead; in humans, a negative correlation has been observed between blood lead levels and plasma selenium levels among workers exposed to lead. ${ }^{22}$ Lead neurotoxicity mechanisms are intricate and include, among other aspects, the oxidative stress generated by free radicals induced by the presence of lead. ${ }^{8}$ So, the dietary presence of minerals and vitamins with antioxidant properties may reduce lead toxicity caused by this pathway. For example, vitamin $\mathrm{C}$ has a well-demonstrated antioxidant property, which is exerted by the inhibition of lipid peroxidation; however, it has also been established that it may have a chelating effect on lead similar to that of ethylenediaminetetraacetic acid (EDTA). In animal studies, it has been observed that vitamin $C$ could have a protective effect against lead-induced hematopoietic toxicity and may also increase lead urinary excretion. Vitamin E-, vitamin B6-, and beta-carotene-rich

TABLE 2. Comparison of daily intake of lead from diet in different countries

\begin{tabular}{|c|c|c|c|c|}
\hline Country & Estimated DI ( $\mu \mathrm{g} /$ day) & Population & Year of publication & Reference \\
\hline United Kingdom & 6 & General & 2010 & Rose et al.(23) \\
\hline Korea & 9.8 & General & 2012 & Koh et al.(24) \\
\hline Denmark & 18 & General & 2002 & Larsen et al.(25) \\
\hline Germany & 19 & General & 2000 & Seifert et al. (26) \\
\hline Japan & 21 & General & 2004 & Maitani et al. (27) \\
\hline Canada & 24 & General & 1995 & Dabeka et al. (28) \\
\hline Spain (Basque Country) & 34 & General & 1996 & Urieta et al. (29) \\
\hline France & 52 & General & 2000 & Leblanc et al. (30) \\
\hline Spain (Catalonia) & 59 & General & 2008 & Marti Cid et al. (11) \\
\hline China & 82 & General & 2007 & Zheng et al. (31) \\
\hline Chile & 206 & General & 2005 & Muñoz et al. (18) \\
\hline La Plata & 138 & Children aged 1 to 7 years & 2017 & Martins et al. \\
\hline
\end{tabular}

DI: daily intake. 
foods may have a protective effect against lipid peroxidation. $^{22}$

This study is the first approximation to a health field that has not been sufficiently studied in Argentina, with a methodology that may be replicated in other age groups and with exposure to other toxic compounds. Further larger studies with bigger populations are required to determine $\mathrm{Ipb}$ in the pediatric population in a more precise manner.

\section{CONCLUSION}

The lead burden of children aged 1 to 7 years attending a public hospital in La Plata is $138 \mu \mathrm{g} /$ day.

\section{REFERENCES}

1. Yu MH, Tsunoda H. Environmental toxicology: biological and health effects of pollutants. 2nd ed. Boca Ratón, FL: CRC Press; 2004.

2. Nordberg GF, Fowler B, Nordberg M, et al. General Considerations and International Perspectives. In: Handbook on the Toxicology of Metals. 3rd ed. California: Elsevier; 2007. Pages 1-9.

3. Zukowska J, Biziuk M. Methodological evaluation of method for dietary heavy metal intake. J Food Sci 2008;73(2):R21-9.

4. Ahamed M, Siddiqui MK. Environmental lead toxicity and nutritional factors. Clin Nutr 2007;26(4):400-8.

5. Neal AP, Guilarte TR. Molecular neurobiology of lead $(\mathrm{Pb}(2+))$ : effects on synaptic function. Mol Neurobiol 2010;42(3):151-60.

6. CDC. Response to Advisory Committee on Childhood Lead Poisoning Prevention Recommendations in "Low Level Lead Exposure Harms Children: A Renewed Call of Primary Prevention". Atlanta 2012. [Accessed on: January $3^{\text {rd }}$, 2017]. Available at:https: / / www.cdc.gov/nceh/Lead/ ACCLPP/CDC_Response_Lead_Exposure_Recs.pdf.

8. ChiodoLM,JacobsonSW,JacobsonJL. Neurodevelopmental effects of postnatal lead exposure at very low levels. NeurotoxicolTeratol 2004;26(3):359-71.

9. Bas P, Luzardo OP, Pena-Quintana L, et al. Determinants of blood lead levels in children: a cross-sectional study in the Canary Islands (Spain). Int J Hyg Environ Health 2012;215(3):383-8.

10. Menezes-FilhoJA, Viana GF, Paes CR. Determinants of lead exposure in children on the outskirts of Salvador, Brazil. Environ Monit Assess2012;184(4):2593-603.

11. Bernard J, McGeehin M. Prevalence of blood lead levels $\geq 5 \mu \mathrm{g} / \mathrm{dL}$ among US children 1 to 5 years of age and socioeconomic and demographic factors associated with blood of lead levels 5 to $10 \mu \mathrm{g} / \mathrm{dl}$, Third National Health and Nutrition Examination Survey, 1988-1994. Pediatrics 2003;112(6 Pt 1):1308-13.

12. Marti-Cid R, Llobet JM, Castell V, et al. Dietary intake of arsenic, cadmium, mercury, and lead by the population of Catalonia, Spain. Biol Trace Elem Res 2008;125(2):120-32.

13. Martins E, Varea A, Hernandez K, et al. Blood lead levels in children aged between 1 and 6 years old in La Plata, Argentina. Identification of risk factors for lead exposure. Arch Argent Pediatr 2016;114(6):543-9.

14. SCOOP. Reports on heavy metals in food. Assessment of the dietary exposure to arsenic, cadmium, lead and mercury of the population of the EU member states.
Brussels 2004. [Accessed on: January $3^{\text {rd }}$, 2017]. Available at: https: / / ec.europa.eu/food/sites/food/files/ safety / docs/cs_contaminants_catalogue_scoop_3-2-11_heavy_ metals_report_en.pdf.

15. Malpeli A, Apezteguia M, Mansur JL, et al. Calcium supplementation, bone mineral density and bone mineral content. Predictors of bone mass changes in adolescent mothers during the 6-month postpartum period. Arch Latinoam Nutr 2012;62(1):30-6.

16. Malpeli A, MansurJL, De Santiago S, et al. Changes in bone mineral density of adolescent mothers during the 12-month postpartum period. Public Health Nutr 2010;13(10):1522-7.

17. EFSA Panel on Contaminants in the Food Chain (CONTAM). Scientific Opinion on Lead in Food. EFSA Journal 2010; 8(4):1570. [Accessed on: January $3^{\text {rd }}$, 2017]. Available at: http://onlinelibrary.wiley.com/ doi/10.2903/j.efsa.2010.1570/epdf.

18. Argentina. Ministerio de Salud. Encuesta Nacional de Nutrición y Salud. Documento de resultados.2007. [Accessed on:January $3^{\text {rd }}$, 2017]. Available at: http: / / www. msal.gob.ar/ images/stories/bes/graficos/0000000257cnta08-ennys-documento-de-resultados-2007.pdf.

19. Muñoz O, Bastias JM, Araya M, et al. Estimation of the dietary intake of cadmium, lead, mercury, and arsenic by the population of Santiago (Chile) using a Total Diet Study. Food Chem Toxicol 2005;43(11):1647-55.

20. Food and Nutrition Board, Institute of Medicine, National Academies. Dietary Reference Intakes for Water, Potassium, Sodium, Chloride, and Sulfate. Washington: National Academies Press; 2005. [Accessed on: January $5^{\text {th }}, 2017$ ] Available at: https:/ / www.nap.edu/read/10925/ chapter/ 1 .

21. Llobet JM, Falcó G, Casas C, et al. Concentrations of arsenic, cadmium, mercury, and lead in common foods and estimated daily intake by children, adolescents, adults, and seniors of Catalonia, Spain. J Agric Food Chem 2003;51(3): $838-42$.

22. Sociedad Argentina de Pediatría. Comité Nacional de Crecimiento y Desarrollo. Guía para la evaluación del crecimiento Físico. 3.ra ed. Buenos Aires: SAP;2013.

23. Sanders T, Liu Y, Buchner V, et al. Neurotoxic effects and biomarkers of lead exposure: a review. Rev Environ Health 2009;24(1):15-45.

24. Rose M, Baxter M, Brereton N, et al. Dietary exposure to metals and other elements in the 2006 UK Total Diet Study and some trends over the last 30 years. Food Addit Contam Part A, Chem Anal Control Expo Risk Assess 2010;27(10): 1380-404.

25. Koh E, Shin H, Yon M, et al. Measures for a closer-to-real estimate of dietary exposure to total mercury and lead in total diet study for Koreans. Nutr Res Pract 2012;6(5):43643.

26. Larsen EH, Andersen NL, Moller A, et al. Monitoring the content and intake of trace elements from food in Denmark. Food Addit Contam 2002;19(1):33-46.

27. Seifert M, Anke M. Alimentary lead intake of adults in Thuringia/Germany determined with the duplicate portion technique. Chemosphere 2000;41(7):1037-43.

28. Maitani T. Evaluation of exposure to chemical substances through foods-exposure to pesticides, heavy metals, dioxins, acrylamide and food additives in Japan. J Health Sci 2004;50(3):205-9.

29. Dabeka RW, McKenzie AD. Survey of lead, cadmium, fluoride, nickel, and cobalt in food composites and estimation of dietary intakes of these elements by Canadians in 1986-1988. J AOAC Int 1995;78(4):897-909.

30. Urieta I, Jalón M, Eguilero I. Food surveillance in the Basque Country (Spain). II. Estimation of the dietary intake of 
20 / Arch Argent Pediatr 2018;116(1):14-20 / Original article

organochlorine pesticides, heavy metals, arsenic, aflatoxin M1, iron and zinc through the Total Diet Study, 1990/91. Food Addit Contam 1996;13(1):29-52.

31. Leblanc JC, Malmauret L, Guerin T, et al. Estimation of the dietary intake of pesticide residues, lead, cadmium, arsenic and radionuclides in France. Food Addit Contam 2000;17(11):925-32.

32. Zheng $N$, Wang $Q$, Zhang $X$, et al. Population health risk due to dietary intake of heavy metals in the industrial area of Huludao City, China. Sci Total Environ 2007;387(1-3): 96104. 
ANNEX

Questionnaire on the frequency of food intake

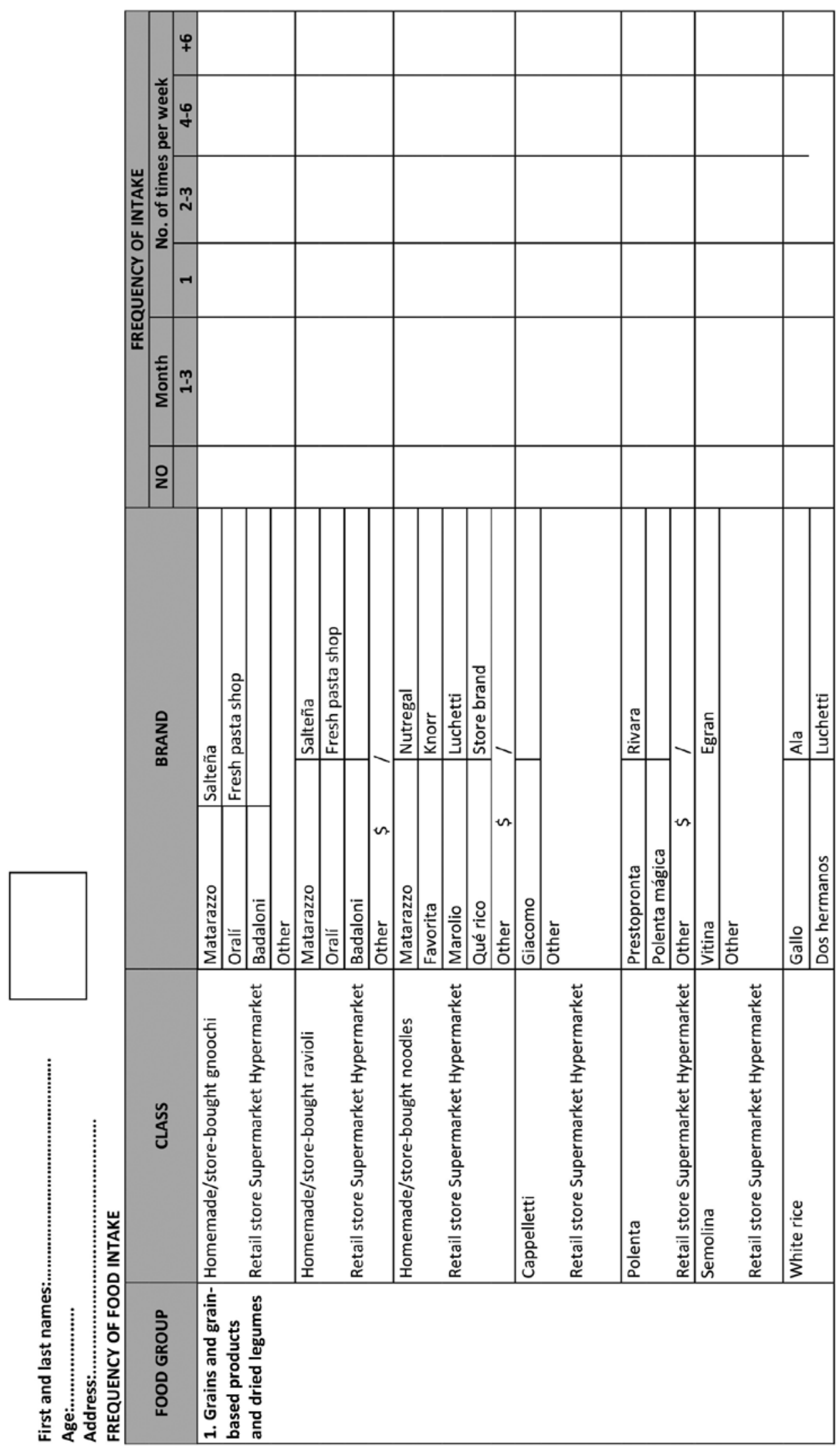




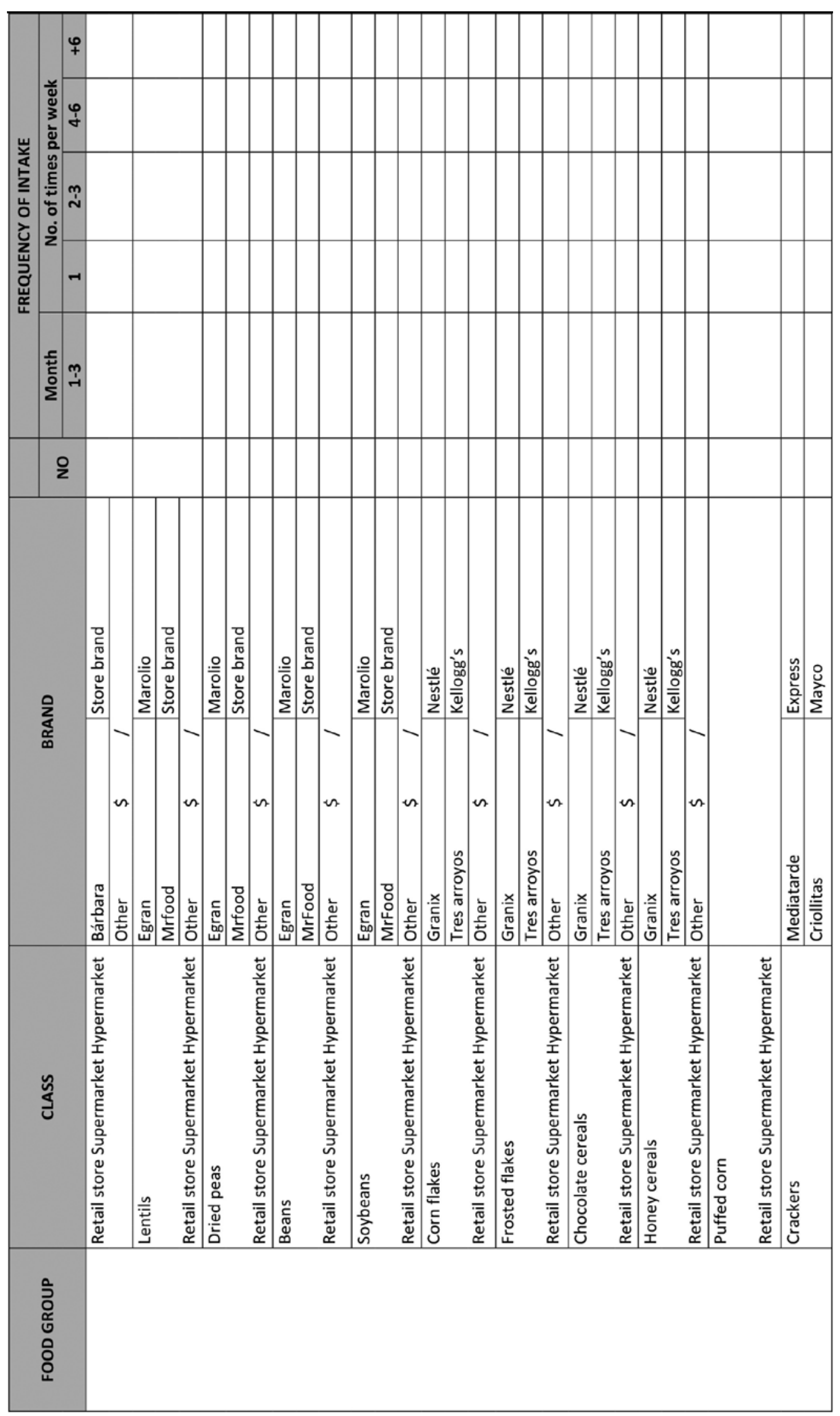




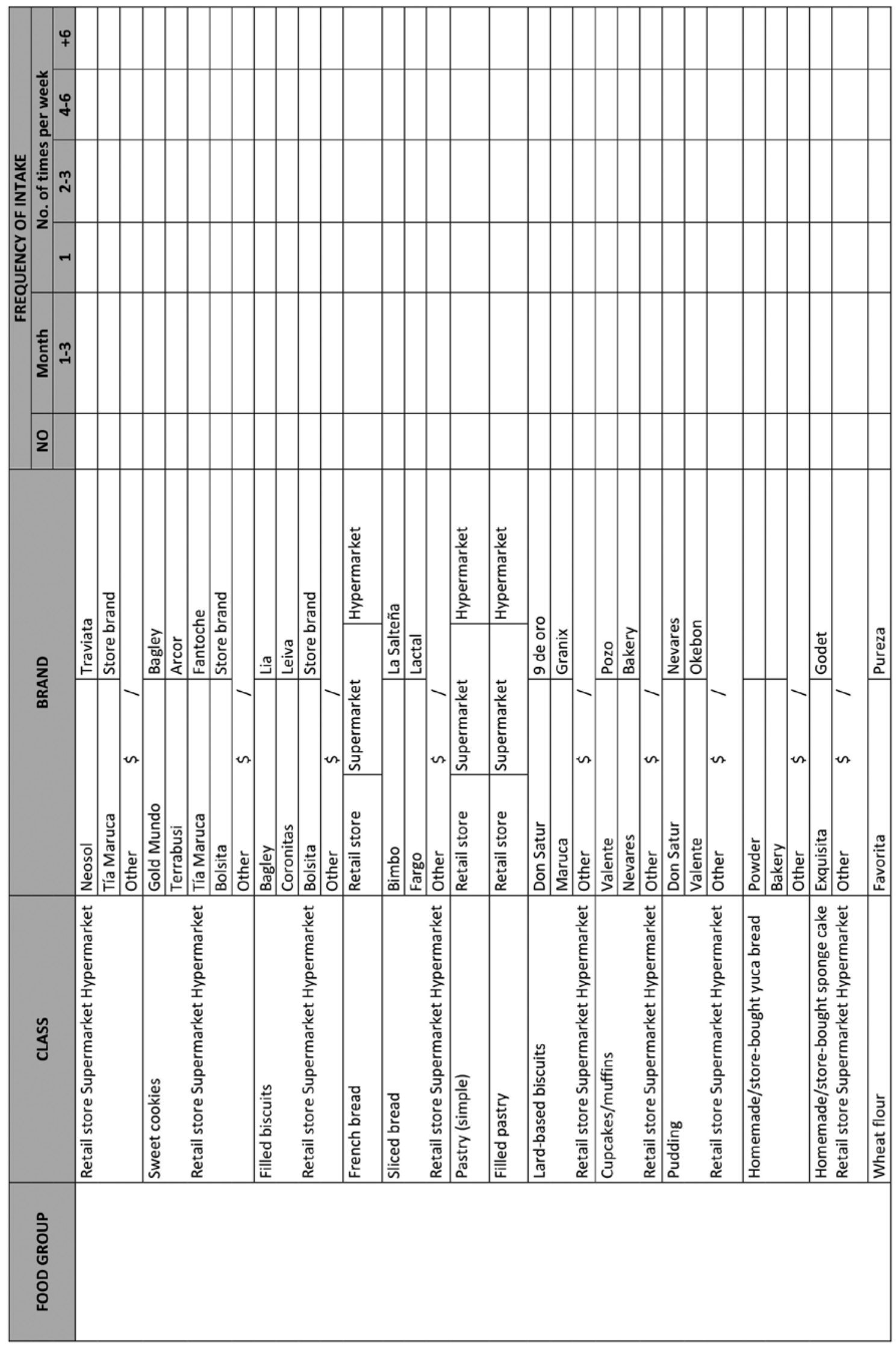




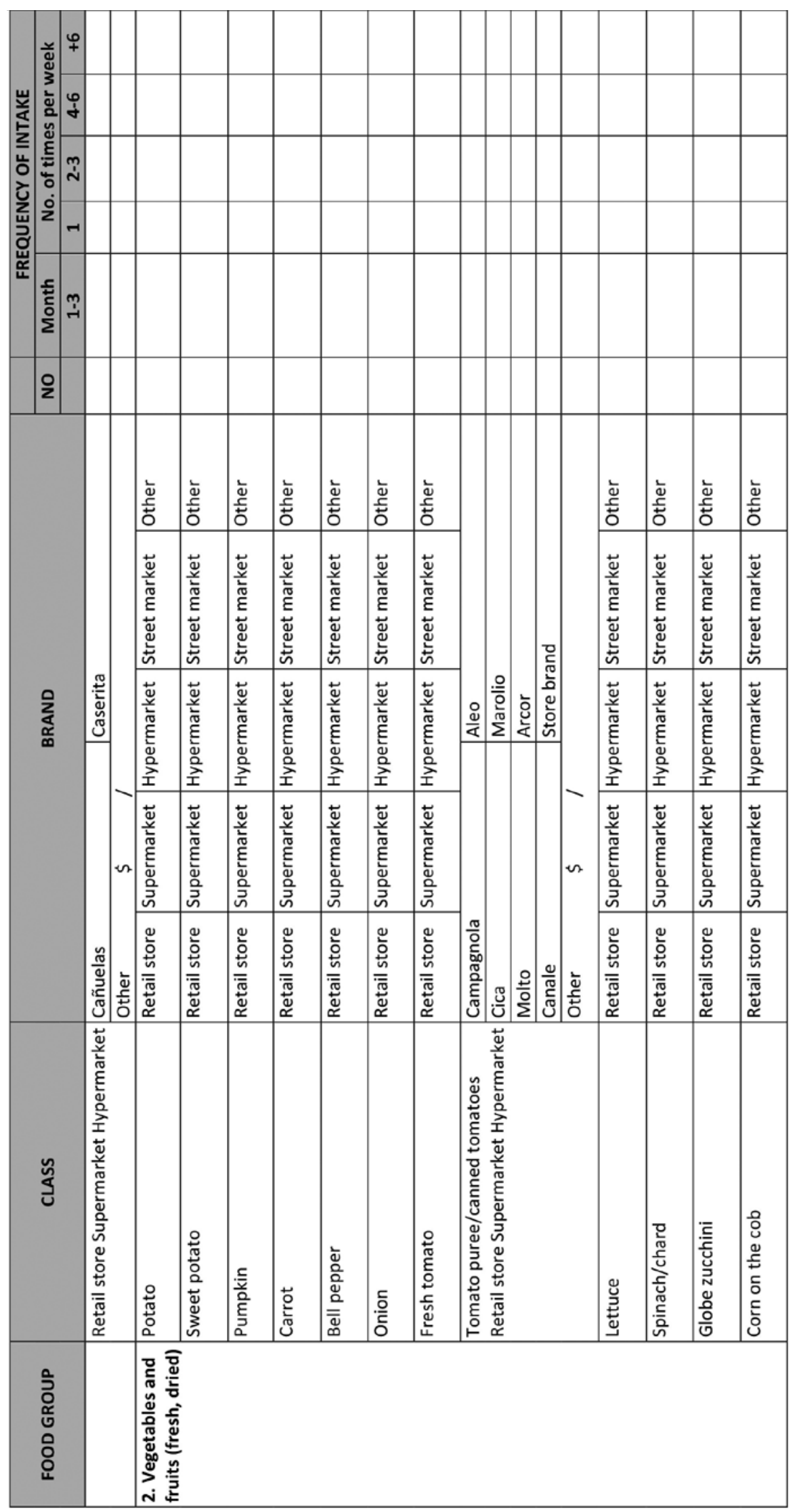




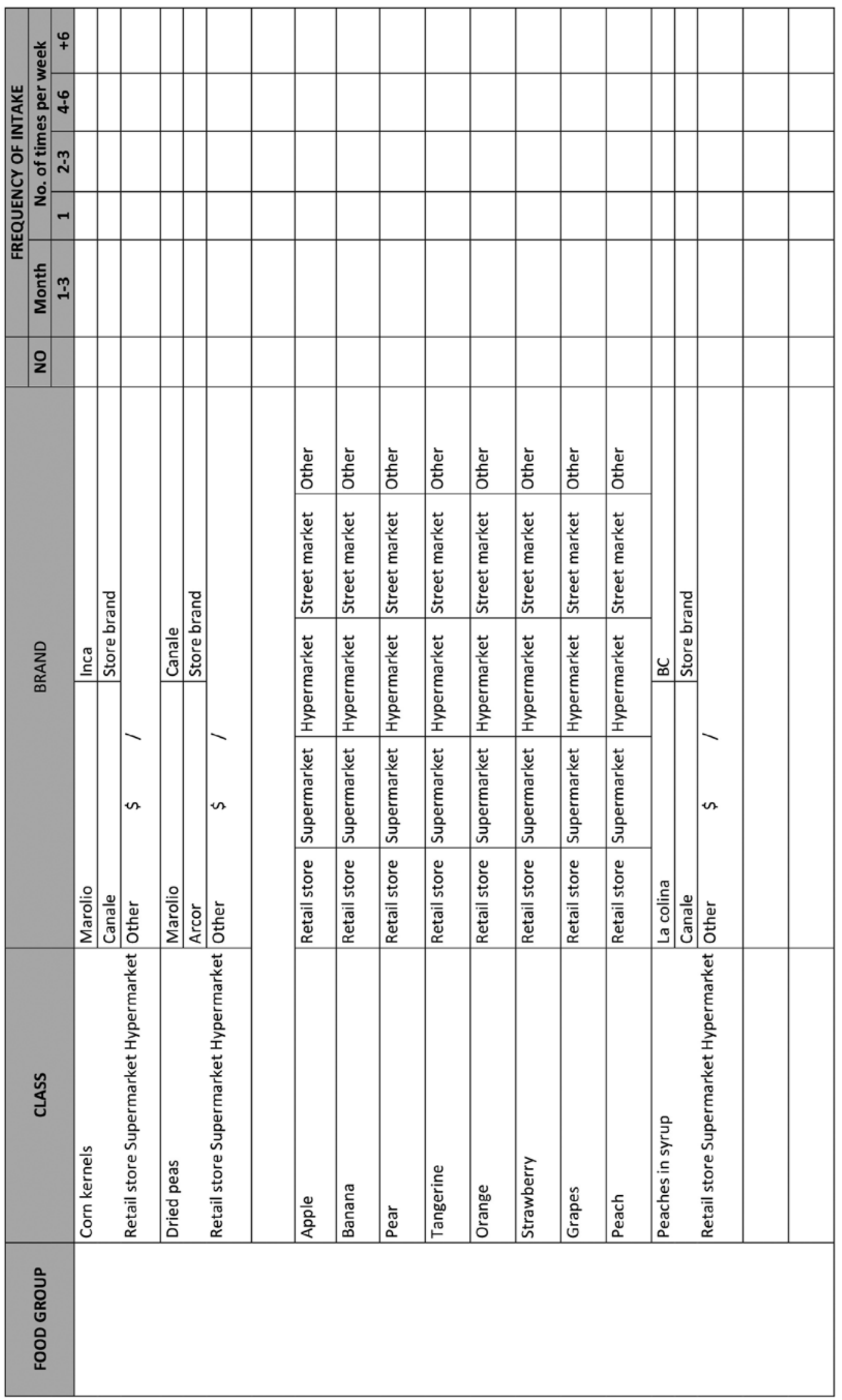




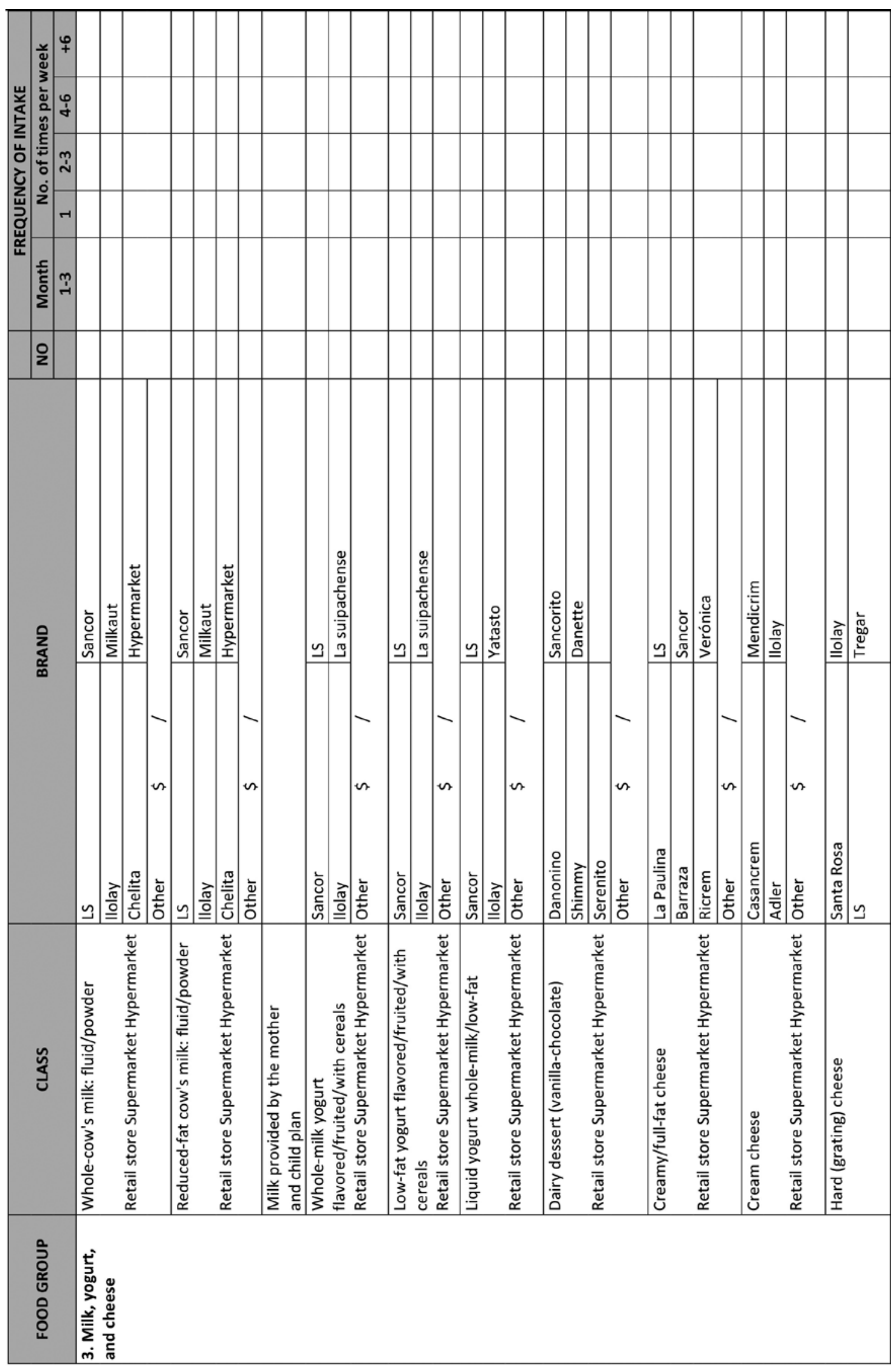




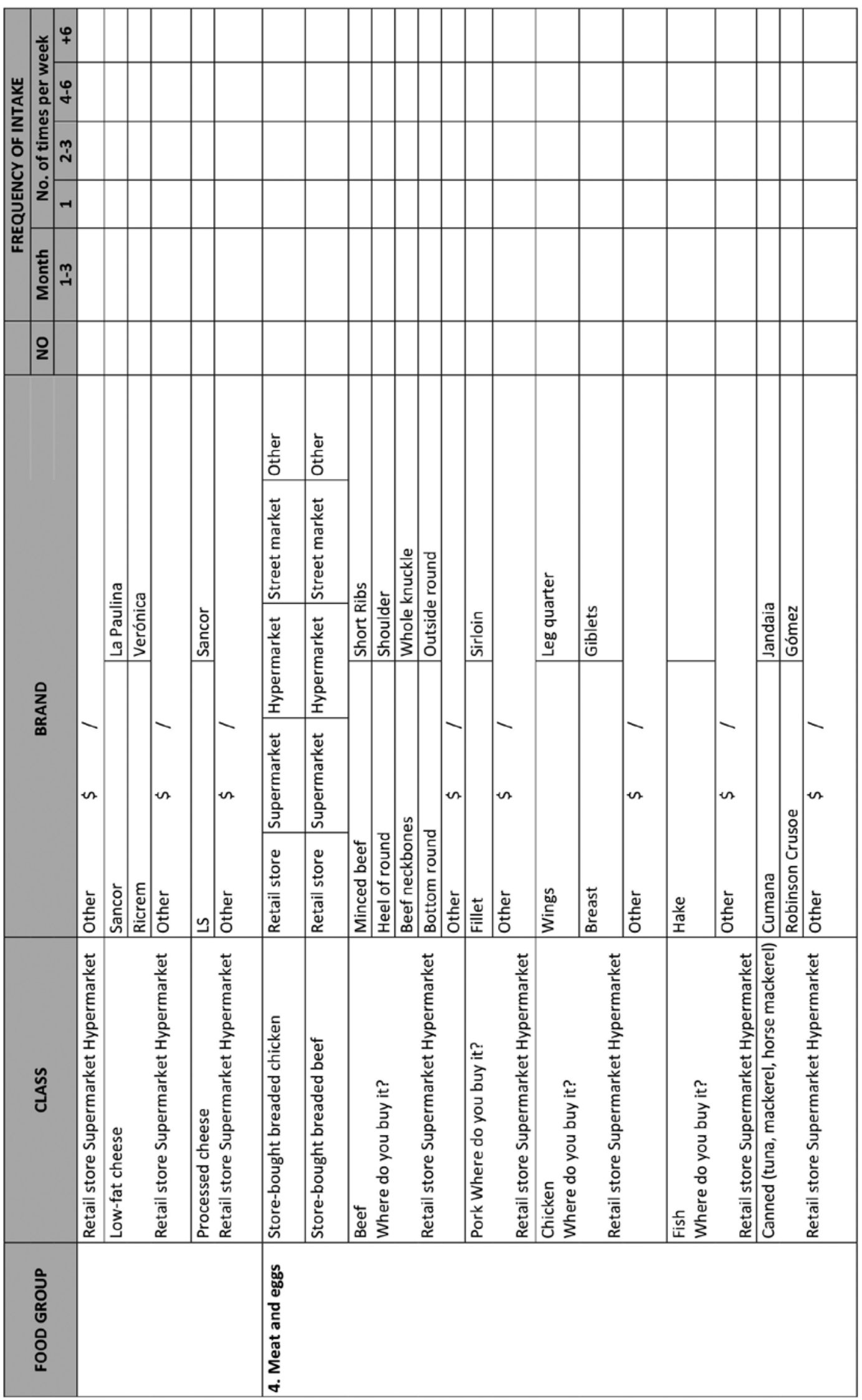




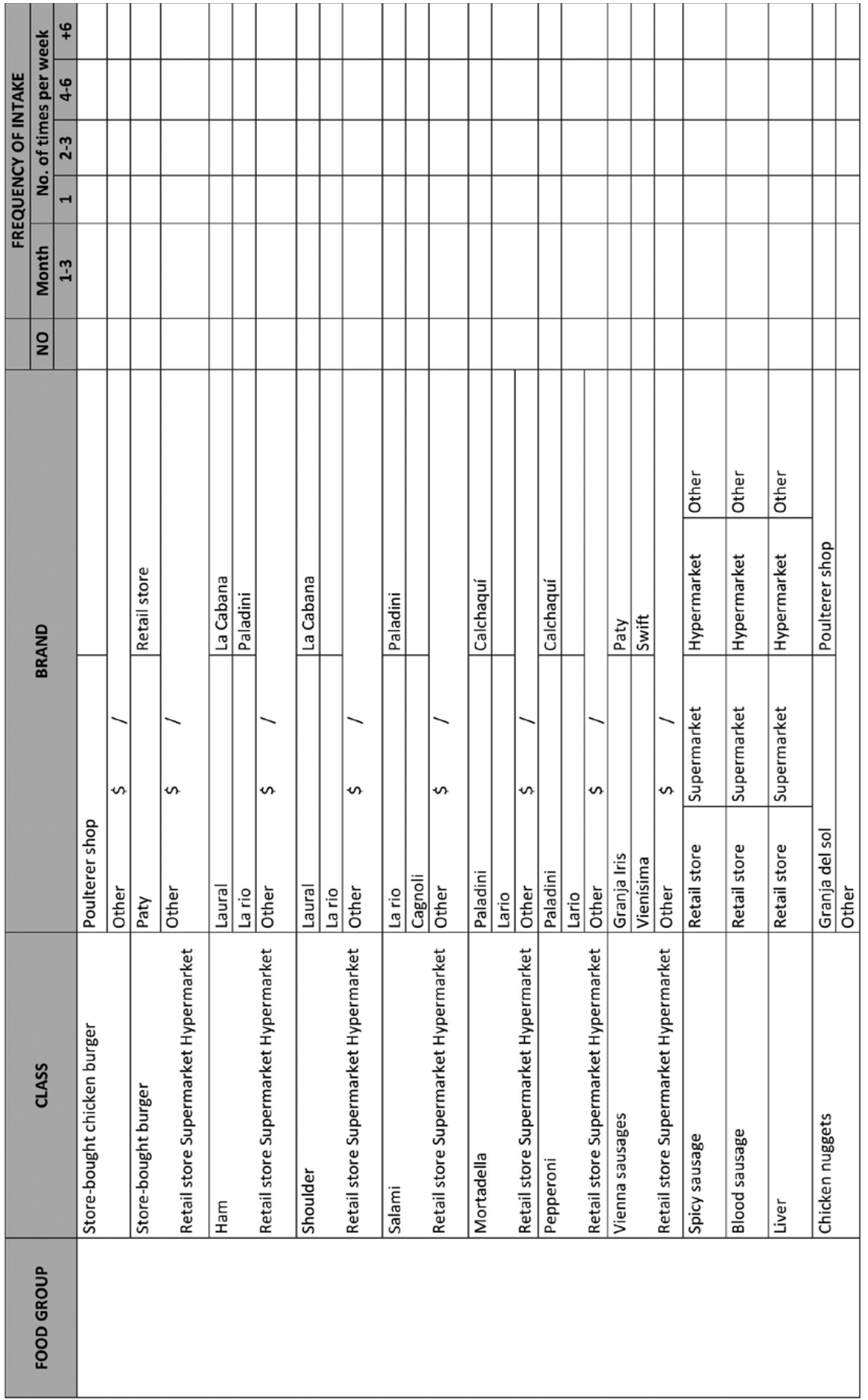




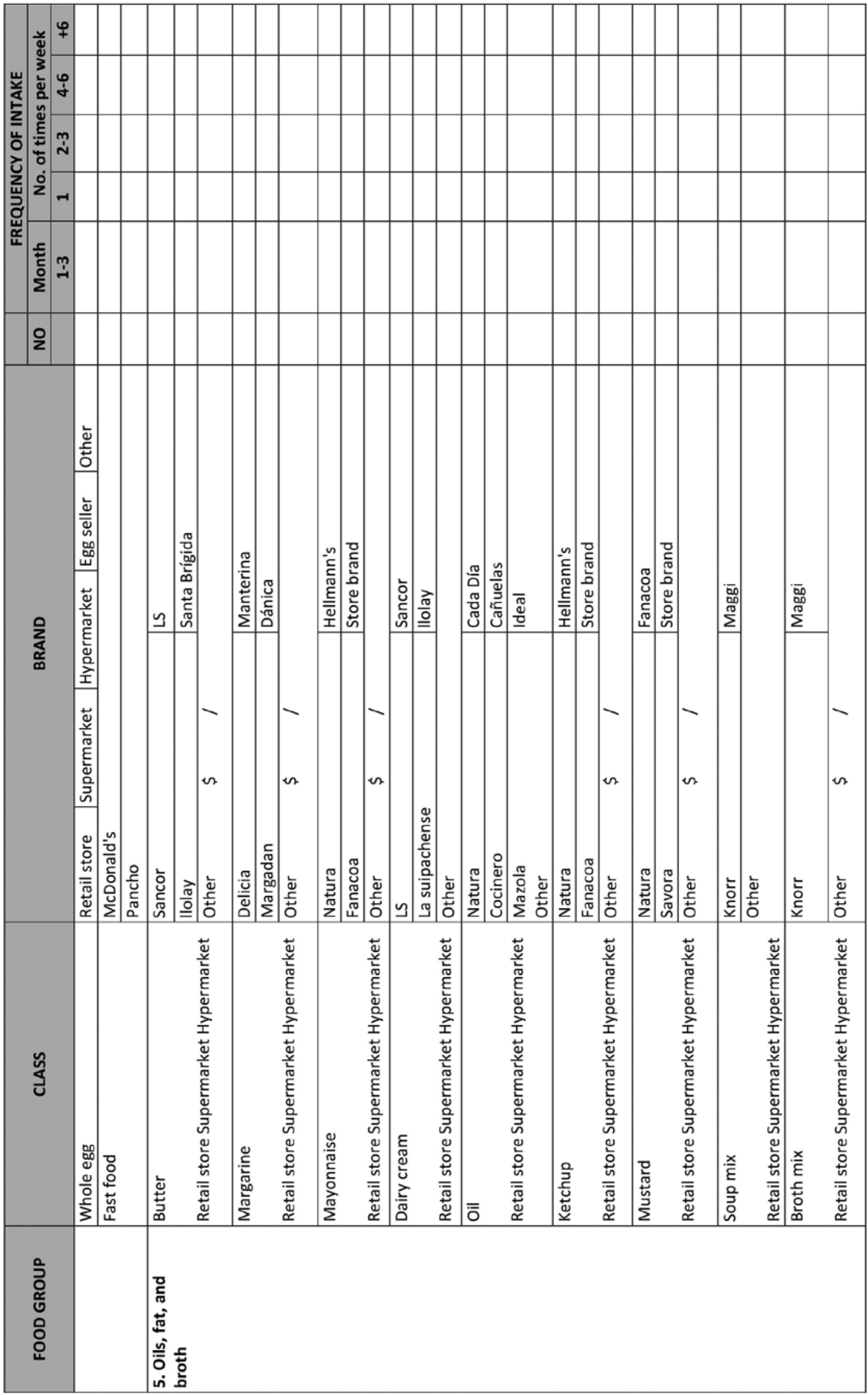




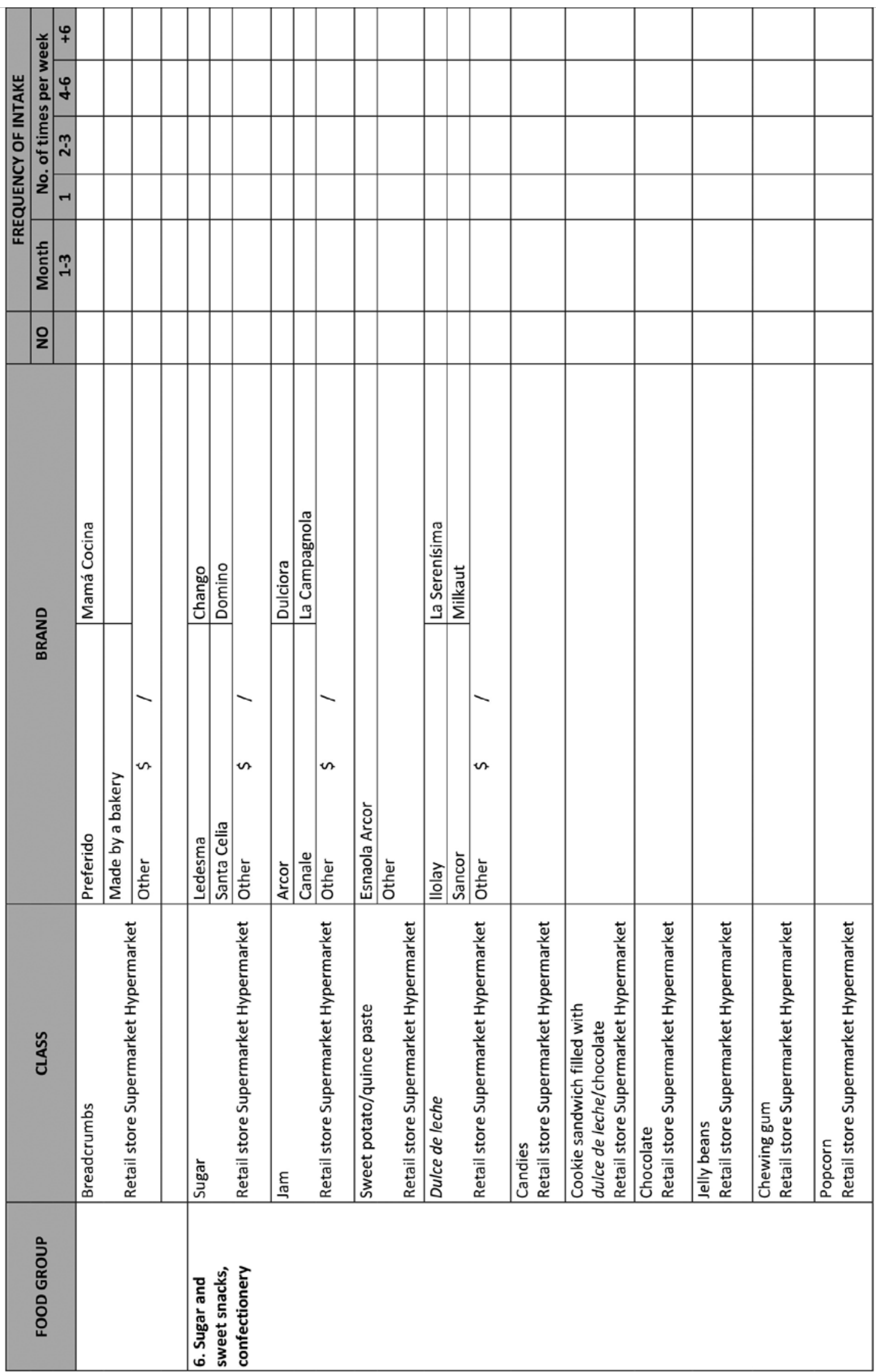




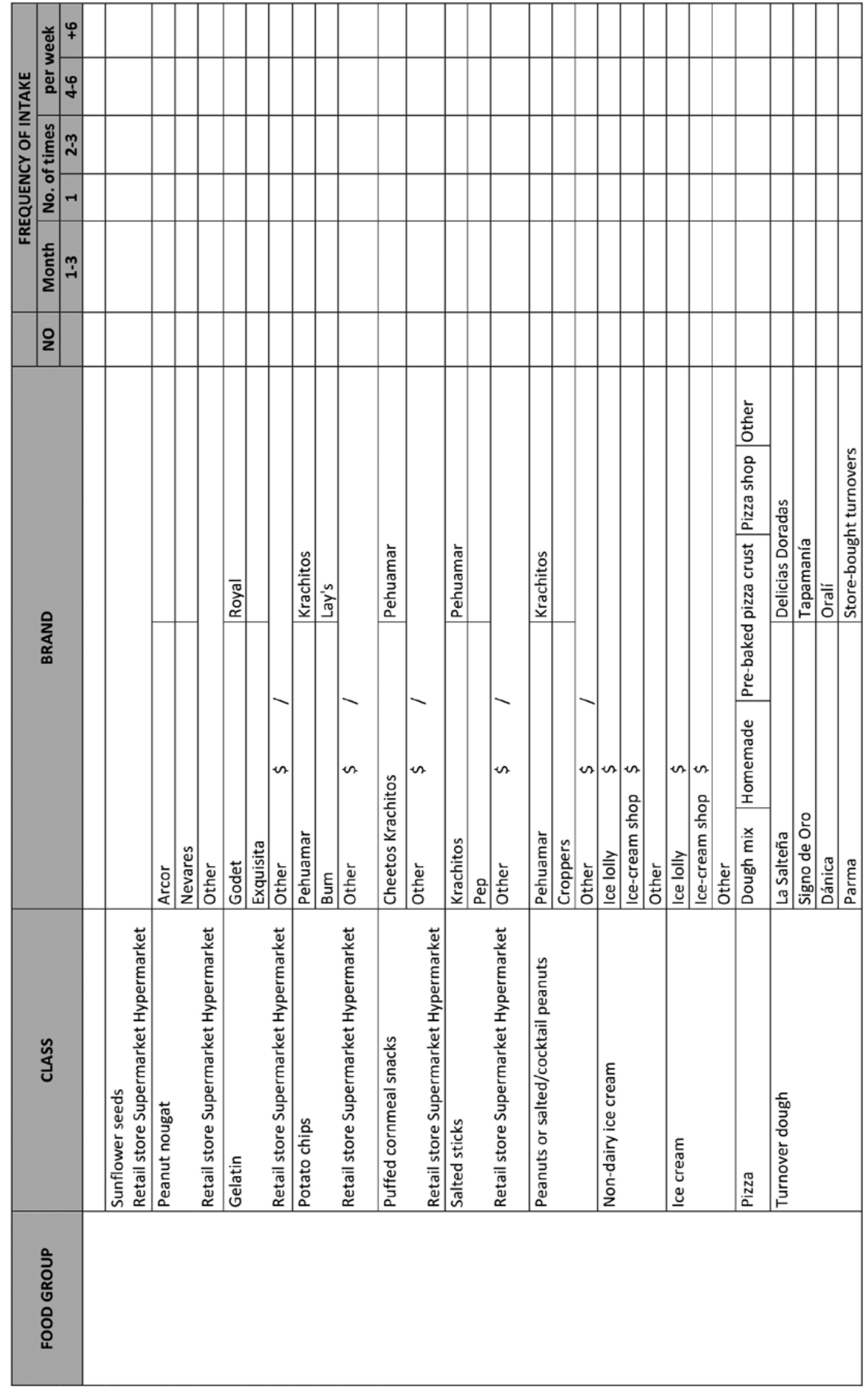




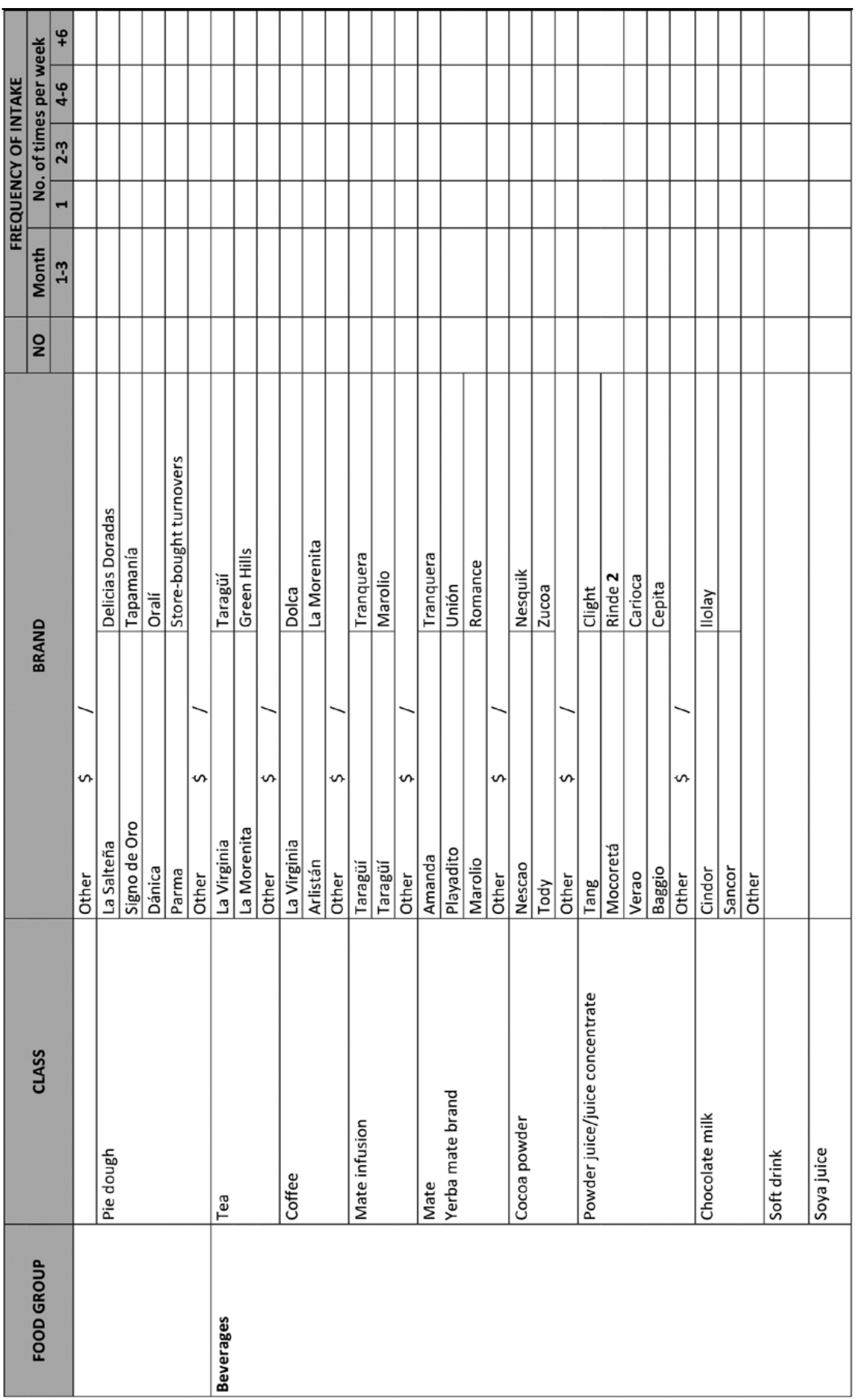


1. What kind of water do you drink?

2. Oil: How many bottles do you buy?

How long does it last?.

How many people share your household?.

3. What seasonings do you use?

Oregano Ground chili pepper Pepper Thyme Pizza seasoning

Other.

Retail store: only retail grocery store, produce shop, bakery or butcher's shop. Supermarket: Asian or retail supermarket that comprises meat, fresh produce, dairy, delicatessen, and baked goods aisles. Hypermarket: Walmart, Carrefour, Nini.

\begin{tabular}{|lll|}
\hline Yesterday was... & & \\
Monday $\quad \square$ & Thursday $\quad \square$ Sunday $\square$ \\
Tuesday $\quad \square$ & Friday $\quad \square$ \\
Wednesday & $\square$ & Saturday $\quad \square$
\end{tabular}

The type of diet we had yesterday was: Like any other day

Different than usual because:

Disease $\square$ On a diet $\square$ Holiday $\square$

Detailed menu:

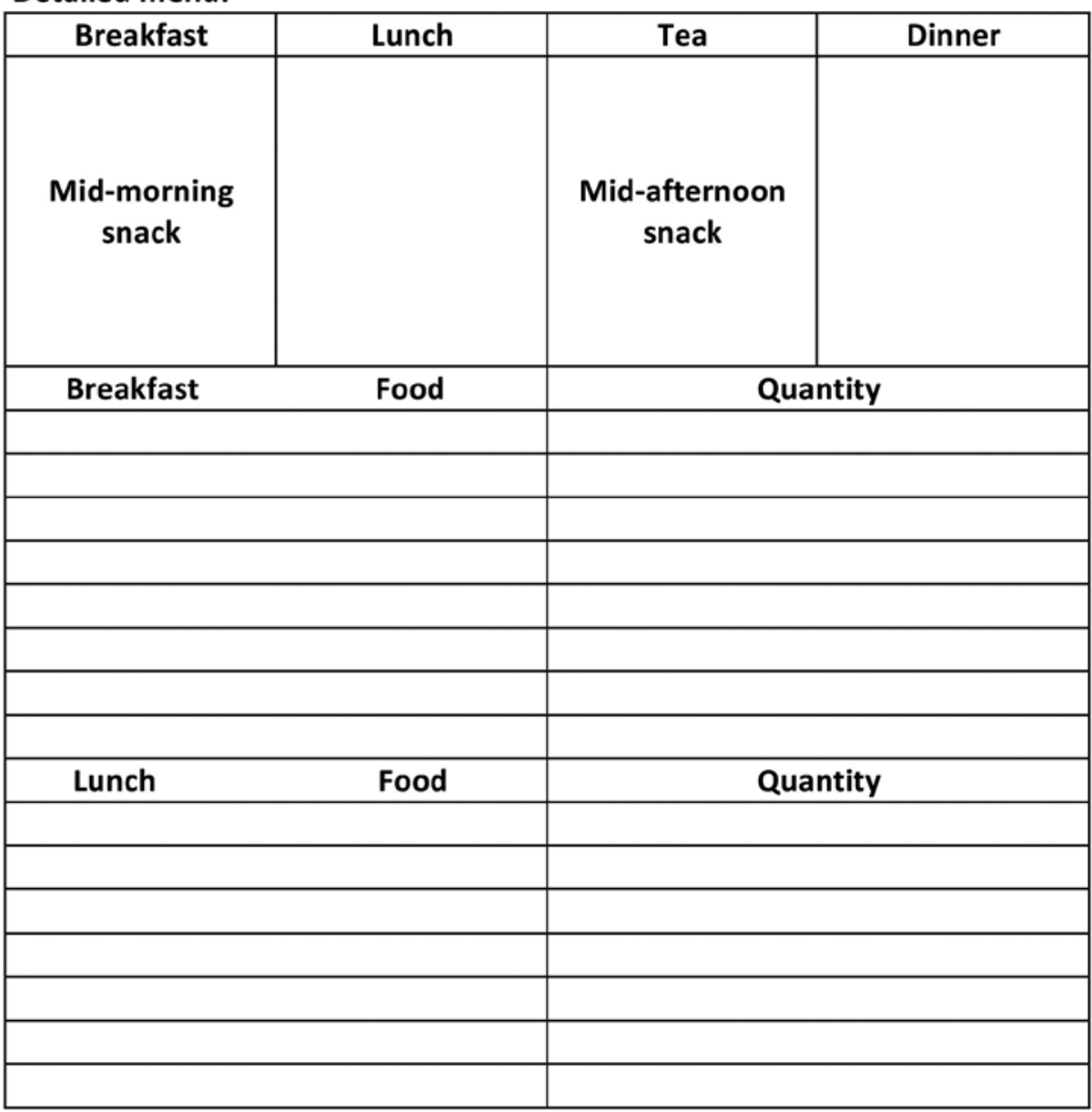




\begin{tabular}{|l|l|}
\hline & \\
\hline & \\
\hline & \\
\hline Tea & \\
\hline & \\
\hline & Quantity \\
\hline & \\
\hline & \\
\hline & \\
\hline & \\
\hline Dinner & \\
\hline & \\
\hline & \\
\hline & \\
\hline & \\
\hline & \\
\hline & \\
\hline & \\
\hline
\end{tabular}

\begin{tabular}{|l|l|l|l|l|l|}
\hline $\begin{array}{l}\text { Food } \\
\text { code }\end{array}$ & Food name & $\begin{array}{l}\text { Net quantity } \\
\text { g/cc }\end{array}$ & $\begin{array}{l}\text { Food } \\
\text { code }\end{array}$ & Food name & $\begin{array}{l}\text { Net quantity } \\
\text { g/cc }\end{array}$ \\
\hline & & & & & \\
\hline & & & & & \\
\hline & & & & & \\
\hline & & & & & \\
\hline & & & & & \\
\hline & & & & & \\
\hline & & & & & \\
\hline & & & & & \\
\hline & & & & & \\
\hline & & & & & \\
\hline
\end{tabular}

